\title{
BREVE RECORRIDO HISTÓRICO de la TEORÍA DE LA RESISTENCIA
}

\author{
Álvaro GARCÍA MARTÍNEZ ${ }^{56}$
}

Sumario: I.Resistencia a La Autoridad A)Teoría de la Resistencia de Thomas Hobbes.

B).-Legitimidad de la Resistencia C).- Resistencia Activa. D).-Resistencia Pasiva.li.La Revolución. A).- Concepto De Revolución .B).- Concepto De Rebelión. C).- La Revolución Constitucional Mexicana De 1913. D). - Aceptación Y Obediencia De Las Nuevas Autoridades Emanadas De Una Constitución, Producto De Una Revolución. lii. Conclusión

\section{I.- RESISTENCIA A LA AUTORIDAD}

A).- TEORÍA DE LA RESISTENCIA AL PODER DE THOMAS HOBBES. Este filósofo y político, fue un convencido de que el PODER SOBERANO era absoluto, de que nada había por encima de él, incluso estaba por encima de la ley. La soberanía decía, radica en el soberano y es indivisible e inalienable; nadie se puede oponer al poder soberano, no puede justificarse nunca la resistencia a la autoridad. "Sin embargo, resultaba también de la teoría de la resistencia, que esta se había de presentar en realidad siempre que el gobierno fuese incapaz de producir aquella seguridad que es la única razón dela sumisión de los súbditos. El único argumento en pro del gobierno consiste en que gobierna en realidad. De ahí, que si la resistencia es afortunada y el soberano pierde su poder, desea ipso facto de ser soberano y sus súbditos de ser súbditos. Se ven arrojados otra vez a sus recursos individuales para su propia protección y pueden justamente dar su propia obediencia a un nuevo soberano capaz de protegerlos". (1) ${ }^{57}$

El concepto de RESISTENCIA A LA AUTORIDAD ("Proviene que la palabra latina resentía - de resisto, ere - que indica la posición que presenta un cuerpo o fuerza a la acción o violencia de otra".) "Se da la resistencia a la autoridad cuando hay un

\footnotetext{
${ }^{56}$ Profesor de Asignatura Indeterminado, Departamento de Derecho, Universidad de Sonora

${ }^{57}$ George H. Sabine, Historia de la Teoría Política, 1945, Fondo de Cultura Económica, S.A. de C.V.
} 
rechazo, por parte de un individuo o una colectividad, realizado fuera de las vías institucionales, de un determinado mandato o ley de la autoridad, como consecuencia de la consideración de ese mandato o ley como injusto. También puede producirse resistencia respecto de todo un sistema político...." (2)

Siempre ha sido motivo de análisis y discusión para la filosofía del derecho y los más destacados constitucionalistas, el determinar si existe o no el derecho de resistencia a la autoridad, inclinándose algunos autores por la negativa absoluta, mientras que otros consideran que existe plena libertad. La declaración de los Derechos del Hombre y del Ciudadano, de la Constitución francesa de 1783, decía en su artículo 35: "CUANDO EL GOBIERNO VIOLE LOS DERECHOS DEL PUEBLO, LA INSURRECCIÓN ES PARA EL PUEBLO Y PARA CADA PORCIÓN DEL PUEBLO EL DERECHO MAS SAGRADO $Y$ EL DEBER MAS INDISPENSABLE."

B).- LEGITIMIDAD DE LA RESISTENCIA. Creemos que el problema central está en determinar la LEGITIMIDAD DEL PODER derivado de la Resistencia o de una Revolución: Thomas Hobbes derivaba la legitimidad de la resistencia y del poder mismo, del incumplimiento por parte del poder soberano, de proporcionar seguridad a los súbditos, pues la seguridad era la razón de ser de su obediencia.

Hobbes no refiere a que tipo de resistencia tenían derecho los súbditos; es decir, si pasiva o activa; sin embargo, al hablar de un triunfo de éstos y de un cambio de autoridad, consideramos que la contempló en su acepción más amplia, pues la resistencia que tenga como propósito el cambio de las estructuras del poder, generalmente termina en resistencia activa.

C).- RESISTENCIA ACTIVA. Normalmente se considera que la resistencia es pasiva, empero, no siempre es así, en ocasiones ésta implica una contra-ofensiva de los atropellos de un gobernante o de todo un sistema político, convirtiéndose en una verdadera Revolución.

\footnotetext{
${ }^{58}$ Diccionario Jurídico Mexicano, Instituto de Investigaciones Jurídicas, UNAM, Editorial Porrúa, S.A. México.
} 
D).- RESISTENCIA PASIVA. Un ejemplo de resistencia pasiva, inerme, la tenemos en GANDHI, para conseguir la independencia de la India con respecto al poder británico. Algunos sostienen que este es un ejemplo clásico de resistencia pacífica que logró el cambio de las estructuras del poder sin derramamiento de sangre, sin embargo, consideramos que sí hubo derramamiento, aunque del lado de la resistencia, tan es así que GANDHI fue asesinado. El movimiento racial de Estados Unidos se ha valido del método de la resistencia, empero no ha estado exento de violencia, pero es pertinente aclarar, la violencia generalmente viene de los grupos racistas.

\section{2.-LA REVOLUCIÓN}

A).- CONCEPTO DE REVOLUCIÓN. Dice el jurista Felipe Tena Ramírez, "entendemos por revolución la modificación violenta de los fundamentos constitucionales de un Estado." (3) ${ }^{59}$ Quizá sea pertinente señalar que en cierta medida, toda revolución en los términos concebidos por Tena Ramírez, implica una resistencia activa, aunque no toda resistencia sea una revolución; De ahí, la importancia de encontrar aunque sea por lo pronto y en este espacio, un respaldo teórico de la Revolución constitucional mexicana de 1913, iniciada por Don Venustiano Carranza para derrocar a Victoriano Huerta y restaurar supuestamente la Constitución de 1857 que se había "violado" al ascender al poder.

B).- CONCEPTO DE REBELIÓN. Proviene del latín rebellionis, acción y efecto de rebelarse: insurrección, levantamiento, alzamiento.

Independientemente del sentido gramatical que se le da al concepto de rebelión, en el Código Penal Federal de México, la considera como delito en su artículo 132 que dice:- "Se aplicará la pena de dos a veinte años de prisión y multa de cinco mil a cincuenta mil pesos a los que, no siendo militares en ejercicio, con violencia y uso de armas traten de:

I.- Abolir o reformar la Constitución Política de los Estados Unidos Mexicanos.

\footnotetext{
${ }^{59}$ Felipe Tena Ramírez, Derecho Constitucional Mexicano, Vigésima Segunda Edición, Pág. 65, Editorial Porrúa, S.A. 
II. Reformar, destruir o impedir la integración de las instituciones constitucionales de la Federación, o su libre ejercicio, y

III.- Separar o impedir el desempeño de su cargo a alguno de los altos funcionarios de la Federación mencionados en el artículo segundo de la Ley de Responsabilidades de los Funcionarios y empleados de la Federación, del Distrito Federal y de los altos Funcionarios de los Estados".

C.- LA REVOLUCIÓN CONSTITUCIONAL MEXICANA DE 1913. Recordemos que en el mes de febrero de 1913, se dio el cuartelazo de la ciudadela en el que Victoriano Huerta aprehendió al legítimo presidente de México Francisco I. Madero y a su vicepresidente Pino Suárez, para posteriormente obligarlos a renunciar a sus cargos, y así en estricto cumplimiento al artículo 81 de la constitución de 1857 ingresara a la presidencia Pedro Lascurain, Secretario de Relaciones Exteriores, quién una vez ya como presidente interino, nombró a Victoriano Huerta como Secretario de Gobernación, renunciando en seguida al cargo, para que el Congreso nombrara a Huerta Presidente de México. Naturalmente que esto no gustó a algunos personajes revolucionarios, entre ellos, Venustiano Carranza quien se levantó en armas en contra de Huerta, aduciendo que se había violentado el precitado precepto Constitucional; es decir, buscaba la restauración de la Constitución de 1857. Afortunadamente las cosas no salieron como las había planteado Don Venustiano Carranza, de solamente reformar dicho documento, sino que el Congreso convirtiéndose en Constituyente creó una nueva Constitución en 1917.

\section{D).- ACEPTACIÓN Y OBEDIENCIA DE LAS NUEVAS AUTORIDADES EMANADAS DE UNA CONSTITUCIÓN PRODUCTO DE UNA REVOLUCIÓN.}

La constitución mexicana de 1917, no deja de ser producto de un movimiento armado que se enderezó en contra de las instituciones formalmente establecidas, aun cuando moralmente reprochable por la forma en que llegó al poder Victoriano Huerta. Es aquí donde se centra la discusión teórica respecto a la validez que pueda tener una Constitución arrancada con violencia, que valida a un gobierno obtenido de la misma manera, y por ende, como obedecerlo, o mejor dicho, por qué lo hemos obedecido. Pues si bien es verdad que en México la soberanía 
radica esencial y originalmente en el pueblo y que éste tiene, en todo tiempo, el inalienable derecho de alterar o modificar la forma de su gobierno, (Art. 39 de la Constitución Política de los Estados Unidos Mexicanos), también lo es que la propia Constitución establece la forma legal en que debe hacerse, como se desprende del artículo 135 que a la letra dice: "La presente Constitución puede ser adicionada o reformad. Para que las adiciones o reformas lleguen a ser parte de la misma, se requiere que el Congreso de la Unión, por el voto de las dos terceras partes de los individuos presentes, acuerde las reformas o adiciones, y que éstas sean aprobadas por la mayoría de las legislaturas de los Estados, El Congreso de la Unión o la Comisión Permanente en su caso, harán el cómputo de los votos de las legislaturas y la declaración de haber sido aprobadas las adiciones o reformas". O sea que definitivamente no hay por la vía legal forma posible de un cambio violento, ni de la constitución, ni de la forma de gobierno. Lo anterior lo confirma el articulo 136 de dicho documento constitucional: "Esta Constitución no perderá su fuerza y vigor, aun cuando por alguna rebelión se interrumpa su observancia. En caso de que por cualquier trastorno público se establezca un gobierno contrario a los principios que ella sanciona, tan luego como el pueblo recobre su libertad, se restablecerá su observancia y con arreglo a ella y a las leyes que en virtud se hubieran expedido, serán juzgados así los que hubieren figurado en el gobierno emanado de la rebelión como los que hubieren cooperado a ésta.

"En 1917, y durante los años que inmediatamente le siguieron, las ideas avanzadas de la Constitución pertenecían a una minoría; una decisión democrática les hubiera sido desfavorable. Hay pues, que convenir en que la Constitución del 17 fue en sus orígenes una Constitución impuesta.

"Pero más tarde la paz se organizó de acuerdo con esta Constitución; su vigencia nadie la discute, sus preceptos están en la base de toda nuestra estructura jurídica y son convocados por todos para justificar o para combatir los actos de los gobernantes. La constitución impuesta ha sido de este modo, ratificada tácitamente por el pueblo mexicano y reconocida como su ley suprema por los países extranjeros". (4)

\footnotetext{
${ }^{60}$ Ibídem. Felipe Tena Ramírez
} 
3.-CONCLUSION. La teoría de la Resistencia al Poder Soberano de Thomas Hobbes y de John Locke, ha sido fuente de inspiración de Legisladores y pueblos en general, pues ha habido Constituciones que plasman el derecho del pueblo a la revolución, como la francesa por ejemplo, otros lo han hecho en su Declaración de Independencia, como los Estados Unidos de Norte América. En México no ha habido, ni lo uno, ni lo otro, sin embargo, se realizó una revolución que dio origen a una nueva Constitución, que a su vez legitimó a la autoridad; circunstancia que tiene como respaldo teórico las ideas de Thomas Hobbes y John Locke, y como respaldo real, el triunfo y apoyo del pueblo mexicano.

\section{BIBLIOGRAFÍA}

1. George H. Sabine (1945) Historia de la Teoría Política, Fondo de Cultura Económica, S.A. de C.V.

2. Diccionario Jurídico Mexicano Instituto de Investigaciones Jurídicas, México:

UNAM.

3. Felipe Tena Ramírez Derecho Constitucional Mexicano Vigésima Segunda Edición, pág. 65, Porrúa, S.A.

4. Felipe Tena Ramírez Derecho Constitucional Mexicano Vigésima Segunda Edición, pág. 65. Porrúa, S.A.

5. Constitución Política de los Estados Unidos Mexicanos.

6. Código Penal Federal. 